The unintended psychological and behavioral drawbacks of big push strategies

\author{
Xin Qin \\ Sun Yat-sen Business School, Sun Yat-sen University \\ qinxin@sysu.edu.cn \\ Kai Chi Yam \\ Business School, National University of Singapore \\ bizykc@,nus.edu.sg \\ Guangrong Ma \\ School of Finance, Renmin University of China \\ grma@ruc.edu.cn
}

Chen Chen

Sun Yat-sen Business School, Sun Yat-sen University

chench28@mail.sysu.edu.cn

Hang Zhu

Sun Yat-sen Business School, Sun Yat-sen University

$\underline{\text { mnszh@mail.sysu.edu.cn }}$

Haixia Wang

School of Journalism and Communication, Jinan University

whxpku@jnu.edu.cn 
**THIS PAPER IS UNDER REVIEW. Please do not use any portion without authors' permission.

This paper may be cited as:

Qin, X., Yam, K. C., Ma, G., Chen, C., Zhu, H., \& Wang, H. (2020). The unintended psychological and behavioral drawbacks of big push strategies. PsyArXiv.

Correspondence concerning this article should be addressed to Dr. Chen Chen, Sun Yat-sen Business School, Sun Yat-sen University, Guangzhou, Guangdong, China. Email: chench28@mail.sysu.edu.cn. 


\section{The unintended psychological and behavioral drawbacks of big push strategies}

Governments and policy makers often adopt big push strategies to help under-developing regions achieve economic growth and shake off poverty. Although numerous studies have documented big push strategies' positive impacts on indicators of economic development (e.g., poverty rate, unemployment rate, etc.), the current research presents evidence of serious psychological and behavioral drawbacks of such policies. Specifically, we examine China's Great Western Development (GWD) Program as a recent prominent example of a big push strategy, in which about 370 million people receive preferential benefits while more than 1 billion people do not. Using a regression discontinuity design based on distance from the boundary of the GWD Program (+/- $100 \mathrm{~km})$, we find that individuals residing in non-GWD regions report higher levels of psychological entitlement compared to their counterparts residing in GWD regions. As a result of increased psychological entitlement, these individuals engage in more selfish behavior and less prosocial behavior. Our results offer initial evidence of the unintended psychological and behavioral consequences of big push strategies.

Keywords: big push strategies; China's Great Western Development Program; psychological entitlement; selfish behavior; prosocial behavior; ethics 


\section{Introduction}

Historically, governments have often employed big push strategies to initiate and speed economic activities in under-developing regions and stimulate deteriorating areas in inner cities (Murphy, Shleifer, \& Vishny, 1989; Rosenstein-Rodan, 1943). Overwhelming evidence has documented the positive effects of big push strategies across different nations and cultures (Busso, Gregory, \& Kline, 2013; Kline \& Moretti, 2014; Sachs, 2006). For example, with a laissez-faire economic model, it took over two hundred years for the United States and Western Europe to gradually industrialize. In contrast, countries in East Asia took only about 40 years to achieve the same level of industrialization with big push strategies (e.g., preferential industrial policies) (Rodrik, 1995; Stiglitz, 2000; World Bank, 1993; Zingales, 2012). Also, a recent study found that the Federal Empowerment Zones Program in the United States has increased workers' wages and decreased unemployment rate, in turn lifting thousands out of poverty (Busso et al., 2013). As a result, many economists have advocated for big push strategies around the world (Sachs, 2006).

While extant research has unpacked the beneficial effects of big push strategies (Busso et al., 2013; Kline \& Moretti, 2014; Sachs, 2006), we have limited knowledge, if any, about their potential drawbacks. Furthermore, extant research on big push strategies has predominantly focused on their impacts on economic indicators (e.g., unemployment rate) (Glaeser \& Gottlieb, 2008; Kline \& Moretti, 2014; Neumark \& Simpson, 2014), largely ignoring its effects on residents' psychological and behavioral reactions. In this research, we suggest that big push strategies will trigger a higher sense of psychological entitlement as well as higher levels of selfish behavior and lower levels of prosocial behavior among those who are left out of such policies. Exploring this proposition is crucial for the numerous countries that have employed or plan to employ big push strategies to speed economic growth and shake off poverty. 


\section{China's Great Western Development Program as a Natural Field Study}

In 2000, the Chinese government initiated the GWD Program. Specifically, 12 provinces in Western China receive preferential treatments on various political, economic, and educational issues to facilitate their growth (Fig. 1). This program covers approximately $71.4 \%$ of mainland China's area (6.9 million $\left.\mathrm{km}^{2}\right)$ and $28.8 \%$ of its population (370 million) (Naughton, 2003). To achieve the ambitious goals of the GWD Program, citizens and businesses in GWD regions receive preferential benefits, such as budgetary resources, credit support, tax incentives, and educational and employment support (Holbig, 2004; Lai, 2002; Naughton, 2003). For instance, the government implements preferential policies for major talent projects such as the national "Thousand Talents Program" and "Ten Thousand Talents Program" to support higher education in GWD regions. Basic medical insurance and training for employment among urban and rural residents are partially subsidized by the government. Firms in the targeted provinces enjoy unique tax breaks (e.g., an income tax rate of 15-25\% compared to the normal rate of $33 \%$ ). In addition, the central government has increased its direct expenditure in the West. Banks are urged by the government to increase their volume of loans to support GWD-related projects, such as infrastructure construction and entrepreneurial pursuits. As a result, the GWD Program has effectively raised Western China's economic development (compared to non-Western regions), including an increase of 25\% in GDP, 79\% in industrial output, and 57\% in physical capital from 1999 to 2014 (Jia, 2019). With its scale, the GWD Program has often been considered one of the most successful big push strategies in recent history.

In this research, we use China's GWD Program as a natural test of the negative psychological and behavioral effects of big push strategies. We propose that the GWD Program leads individuals residing in non-GWD regions to exhibit higher levels of psychological entitlement. Our logic is that a lot of wealth and valuable resources created by 
individuals in non-GWD regions are redistributed by the government to support the economic growth of GWD regions. These policies were implemented by the central government mandatorily, and people residing in non-GWD regions feel compelled to support this program with no choice. We thus suggest that people in non-GWD regions may subsequently feel psychologically entitled for having contributed above and beyond the call of duty and not receiving any benefits in return. This induced psychological entitlement likely leads them to engage in more selfish behavior and less prosocial behavior toward others (Malhotra \& Gino, 2011; Vincent \& Kouchaki, 2016; Zitek, Jordan, Monin, \& Leach, 2010).

\section{Samples and Measures}

We recruited 1,247 individuals (48.4\% female, age $18-65, M=32.2, \mathrm{SD}=9.8)$ residing in counties within $100 \mathrm{~km}$ of the GWD Program boundary to participate in the current study. ${ }^{12}$ In particular, in line with prior economic and psychological studies conducted in China (Talhelm et al., 2014), we only included ethnically Han Chinese participants in the analysis because other minorities might receive further incentives in addition to those from the big push strategies. We also excluded the province of Inner Mongolia (which belongs to the GWD Program) because the ethnic minorities, languages, and religions in Inner Mongolia are vastly different compared to the rest of China (Talhelm et al., 2014). In sum, our participants came from a total of 170 counties from eight provinces. Among them, a total of 83 counties from four provinces (i.e., Chongqing, Guangxi, Hubei [Enshi as a prefecture], and Shaanxi) have received preferential treatment from the GWD Program, and 87 counties from five provinces (Guangdong, Henan, Hubei, Hunan, and Shanxi) have not.

\footnotetext{
${ }^{1}$ Because of the lack of a well-accepted two-dimensional regression discontinuity (RD) optimal bandwidth (Dell \& Olken, 2017), we limit the sample to counties within $100 \mathrm{~km}$ across the boundary. To ensure that our estimates are robust to the specific bandwidth choices, we also report the robustness of our estimates to smaller ranges (50 km and $75 \mathrm{~km})$. 2 our raw data and syntax are available via this anonymous link: https://osf.io/frspt/?view_only=c725b8480ebf410f903c303bf38d91cd.
} 
Participants completed an online survey, which first measured their psychological entitlement with nine items (Campbell, Bonacci, Shelton, Exline, \& Bushman, 2004) $(M=$ $3.197, \mathrm{SD}=0.712, \alpha=0.860$; an example item is "I necessarily deserve special treatment"). Then, we behaviorally measured participants' selfish and prosocial behavior, respectively. Finally, participants reported their demographic information.

Specifically, to measure participants' selfish behavior, we used the "dictator game," a single-trial economic game to measure individuals' selfishness (Fehr \& Fischbacher, 2003; Harbaugh, Mayr, \& Burghart, 2007; Rand, Greene, \& Nowak, 2012; Rand et al., 2009). Participants were informed that they were playing a bonus point allocation game with an anonymous partner over the Internet. Participants were given 10 points and were informed that their task in this game was to decide the allocation scheme. They were asked to decide the number of points they wanted to assign to their partner, and they would keep the rest of the points for themselves. These points could be converted into cash at the end of the study. Further, participants were informed that their decision would be anonymous to the partner and that once the decision had been made, their partner could only accept it. In sum, the points participants allocated to themselves represent their selfishness (complete instructions for the dictator game are presented in Supplementary Text).

We measured prosocial behavior by focusing specifically on helping behavior, which has been widely used to behaviorally assess individuals' prosociality (Vohs, Mead, \& Goode, 2006). Specifically, at the end of the study, participants were asked if they would like to help researchers by completing another survey without any financial incentives (i.e., yes $=1$ or no $=0$ ). Participants were further told that this task would take an additional five minutes and that their decision would not affect the amount of compensation they received in the study (complete instructions for assessing prosocial behavior are presented in Supplementary Text).

\section{Econometric Model}


The large imbalance between the Western and non-Western areas will potentially confound any simple ordinary least squares (OLS) estimates. To draw reliable causal inferences, we use a spatial regression discontinuity (RD) design (Lee \& Lemieux, 2010). It is worth noting that, RD design is "a way of estimating treatment effects in a nonexperimental setting where treatment is determined by whether an observed assignment variable" (Lee \& Lemieux, 2010). It is considered as a "quasi-experimental" design and has been widely used to test the causal effect of treatment on outcomes in a variety of fields such as economics, education, biostatistics, and environment (Anderson, 2018; Chen, Ebenstein, Greenstone, \& Li, 2013; Ebenstein, Fan, Greenstone, He, \& Zhou, 2017; Jacob \& Lefgren, 2004; Lalive, 2007; Lee, 2008). Specifically, our empirical strategy applies the discontinuous change in exposure to the GWD Program across the policy boundary. Our basic regression is

$$
Y_{i}=\beta_{0}+\beta_{1} \text { West }_{i}+f\left(\text { distance }_{i}\right)+\epsilon_{i}
$$

where $Y_{i}$ is the outcome variable of interest in county $i$; West $t_{i}$ is a binary indicator, which equals 1 if county $i$ is involved in the GWD Program and 0 otherwise; distance $e_{i}$ is county $i$ 's distance from the boundary in kilometers, which is the running variable; $f($ distance) is $a$ functional form that indicates the order of polynomial regression to account for the different slopes on the two sides of the boundary; and $\beta_{1}$ captures the treatment effect of the GWD Program, our main point of interest.

As discussed by recent scholars (Lee \& Lemieux, 2010), equation (1) can be estimated with a non-parametric local approach, which uses a narrow bandwidth near the boundary and controls for a polynomial of distance $_{i}$. In our baseline regression, we limit the sample to counties within $100 \mathrm{~km}$ of the boundary and control for a quadratic polynomial of distance $_{i}$ (Fig. 2). To ensure that our estimates are robust to the specific bandwidth choice, we also report the robustness of our estimates to smaller ranges (50 km and $75 \mathrm{~km}$ ). To verify the robustness of the polynomial order, we also report results controlling for linear 
polynomials.

The validity of our identification design relies on the "smoothness assumption" that people across the boundary of the GWD Program are demographically and culturally similar (Imbens \& Lemieux, 2008). We examine the following demographic characteristics: gender, hukou status, ${ }^{3}$ age, education, and annual income. Specifically, we estimate regressions of the form described in equation (1) using these characteristics as dependent variables. To be consistent with our baseline specifications, we limit our analyses to counties within $100 \mathrm{~km}$ of the boundary and adopt the quadratic approach. Table 1 shows that these characteristics are not significantly different across the boundary $(p s>0.221)$.

\section{Results}

Table 2 presents our baseline results. Estimates from the quadratic polynomials reveal that, people in non-GWD regions are significantly more entitled than their counterparts residing in GWD regions, representing a difference of $0.479(95 \%$ confidence interval $(\mathrm{CI})=$ 0.178 to 0.779 ). Similarly, people residing in non-GWD regions are significantly more selfish (a difference of $0.642 ; 95 \%$ CI: 0.064 to 1.221 ) and less prosocial (a difference of -0.316 ; 95\% CI: $-0.503,-0.129)$, compared to their counterparts residing in GWD regions.

Furthermore, the results in Table 3 reveal that psychological entitlement significantly mediates the impacts of the GWD Program on selfish behavior $(b=0.183, p<0.01$; an indirect effect estimate $=-0.088,95 \% \mathrm{CI}:-0.175,-0.023)$ and prosocial behavior $(b=-0.049$, $p<0.01$; an indirect effect estimate $=0.023,95 \%$ CI: 0.004, 0.050).

Our baseline results for psychological entitlement, selfish behavior, and prosocial behavior can be seen graphically in Figures 3, 4, and 5, respectively. The continuous solid line represents the predicted values fitted by a quadratic polynomial in distance separately for counties on each side of the boundary. Each point, weighted by the number of counties,

\footnotetext{
3 The hukou system was introduced in China in the 1950s. Chinese citizens are classified into rural hukou or non-rural hukou, and to some extent, one's hukou reflects one's identity and social status in China.
} 
represents the average score within 5-km intervals. The clear jump at the boundary suggests that the GWD Program is associated with significant differences among citizens residing within +/- $100 \mathrm{~km}$ of the GWD Program boundary in terms of psychological entitlement, selfish behavior, and prosocial behavior.

\section{Robustness Checks}

Table S1 illustrates the robustness of our results to alternative ranges (i.e., $50 \mathrm{~km}$ or $75 \mathrm{~km})$. Tables S2 and S3 shows the robustness of our results using linear polynomials and without controlling for personal demographics. Furthermore, we split our boundary into five segments of equal length and generate indicator functions, $\operatorname{Seg}_{S}$, that equal 1 if county $i$ is closest to segment $s$ and 0 otherwise. Controlling for segment dummies enables us to compare people across the same segment of the boundary. Table S4 shows the robustness of further controlling segment fixed effects. In Table S5, we exclude participants whose birth county is different from where they currently reside. All the results are similar to our baseline results in terms of significance levels and coefficients. Table S6 shows the heterogeneity effects. The results show there is no heterogeneity among people of different gender, hukou status, age, education, or income.

\section{Discussion}

The results reveal that the GWD Program, a big push strategy that was initiated to facilitate the economic growth of China's Western provinces, has unintended adverse consequences for individuals' psychological states and behaviors. Specifically, it leads to an increase in psychological entitlement, and in turn an increase in selfish behavior and a decrease in prosocial behavior among citizens residing in non-GWD regions.

Our findings have several implications for both big push strategies specifically and social policies in general. To date, policy and economic analysts have emphasized the benefits that big push strategies exert through their economic effects. Our research suggests 
that this perspective overestimates the net benefits of such policies. That is, although the

GWD Program was designed to have significant impacts on economic growth, our results suggest that it might also make more than 1 billion people in non-GWD regions feel more entitled and behave more selfishly and less prosocially in their daily lives as a result. More broadly, these findings may be leveraged to design policies so that we can enjoy the sparks of big push strategies while mitigating their costs.

\section{References}

Anderson, S. (2018). Legal origins and female HIV. American Economic Review, 108(6), 1407-1439.

Busso, M., Gregory, J., \& Kline, P. (2013). Assessing the incidence and efficiency of a prominent place based policy. American Economic Review, 103(2), 897-947.

Campbell, W. K., Bonacci, A. M., Shelton, J., Exline, J. J., \& Bushman, B. J. (2004). Psychological entitlement: Interpersonal consequences and validation of a self-report measure. Journal of Personality Assessment, 83(1), 29-45.

Chen Y, Ebenstein A, Greenstone M, Li H. (2013). Evidence on the impact of sustained exposure to air pollution on life expectancy from China's Huai River policy. Proceedings of the National Academy of Sciences of the United States of America, 110(32), 12936-12941.

Dell, M., \& Olken, B.A. (2017). "The development effects of the extractive colonial economy: The dut ch cultivation system in java" (NBER Working Paper No. 24009; https://www.nber.org/papers/w 24009). [the easiest access to this source is via the URL].

Ebenstein A, Fan M, Greenstone M, He G, Zhou M. (2017). New evidence on the impact of sustained exposure to air pollution on life expectancy from China's Huai River Policy. Proceedings of the National Academy of Sciences of the United States of America,114(39):10384-10389.

Fehr, E., \& Fischbacher, U. (2003). The nature of human altruism. Nature, 425(6960), 785-791.

Glaeser, E.L., \& Gottlieb, J.D. (2008) “The economics of place-making policies” (NBER Working Paper No. 14373; https://www.nber.org/papers/w14373). [the easiest access to this source is via the URL].

Harbaugh, W. T., Mayr, U., \& Burghart, D. R. (2007). Neural responses to taxation and voluntary giving reveal motives for charitable donations. Science, 316(5831), 1622-1625.

Holbig, H. (2004). The emergence of the campaign to open up the West: Ideological formation, central decisionmaking and the role of the provinces. The China Quarterly, 178, 335-357.

Imbens, G. W., \& Lemieux, T. (2008). Regression discontinuity designs: A guide to practice. Journal of Econometrics, 142(2), 615-635.

Jacob, B. A. \& Lefgren, L. (2004). Remedial education and student achievement: A regression-discontinuity analysis. Review of Economics and Statistics, 86(1), 226-244.

Jia, J., Ma, G., Qin, C., \& Wang, L. (2019). The Big Push and State-Led Industrialization: Evidence from China's Great Western Development Program. Working paper.

Kline, P., \& Moretti, E. (2014). People, places, and public policy: Some simple welfare economics of local economic development programs. Annual Review of Economics, 6(1), 629-662. 
Lai, H. H. (2002). China's western development program: Its rationale, implementation, and prospects. Modern China, 28(4), 432-466.

Lalive, R. (2007). Unemployment benefits, unemployment duration, and post-unemployment jobs: A regression discontinuity approach. American Economic Review, 97(2), 108-112.

Lee, D. S. (2008). Randomized experiments from non-random selection in U.S. house elections. Journal of Econometrics, 142(2), 675-697.

Lee, D. S., \& Lemieux, T. (2010). Regression discontinuity designs in economics. Journal of Economic Literature, 48(2), 281-355.

Malhotra, D., \& Gino, F. (2011). The pursuit of power corrupts: How investing in outside options motivates opportunism in relationships. Administrative Science Quarterly, 56(4), 559-592.

Murphy, K. M., Shleifer, A., \& Vishny, R. W. (1989). Industrialization and the big push. Journal of Political Economy, 97(5), 1003-1026.

Naughton, B. (2003) "[How much can regional integration do to unify China's markets?]" in How Far Across the River? Chinses Policy Reform at the Millennium (Stanford, California, N. Hope, D. Yang, M. Y. Li, eds. 2003), pp. 204-232.

Neumark, D., \& Simpson, H. (2014). “Place-based policies” (NBER Working Paper No. 20049; https://www.nber.org/papers/w20049). [the easiest access to this source is via the URL].

Rand, D. G., Greene, J. D., \& Nowak, M. A. (2012). Spontaneous giving and calculated greed. Nature, 489(7416), 427-430.

Rand, D. G., Pfeiffer, T., Dreber, A., Sheketoff, R. W., Wernerfelt, N. C., \& Benkler, Y. (2009). Dynamic remodeling of in-group bias during the 2008 presidential election. Proceedings of the National Academy of Sciences, 106(15), 6187-6191.

Rodrik, D. (1995). Trade Strategy, Investment and Exports: Another Look at East Asia. CEPR Discussion Papers 1305.

Rosenstein-Rodan, P. N. (1943). Problems of industrialisation of eastern and south-eastern Europe. The economic journal, 53(210/211), 202-211.

Sachs, J. D. (2006). The end of poverty: economic possibilities for our time: Penguin.

Stiglitz, J. E. (2000) Economics of the Public Sector (3rd ed.). New York: W.W. Norton \& Company.

Talhelm, T., Zhang, X., Oishi, S., Shimin, C., Duan, D., Lan, X., \& Kitayama, S. (2014). Large-scale psychological differences within China explained by rice versus wheat agriculture. Science, 344(6184), 603-608.

Vincent, L. C., \& Kouchaki, M. (2016). Creative, rare, entitled, and dishonest: How commonality of creativity in one's group decreases an individual's entitlement and dishonesty. Academy of Management Journal, 59(4), 1451-1473.

Vohs, K. D., Mead, N. L., \& Goode, M. R. (2006). The psychological consequences of money. Science, 314(5802), 1154-1156.

World Bank. (1993) The East Asian Miracle: Economic Growth and Public Policy, World Bank Policy Research Report. New York: Oxford University Press.

Zingales, L. (2012). A capitalism for the people: Recapturing the lost genius of American prosperity: Basic books.

Zitek, E. M., Jordan, A. H., Monin, B., \& Leach, F. R. (2010). Victim entitlement to behave selfishly. Journal of Personality and Social Psychology, 98(2), 245-255. 


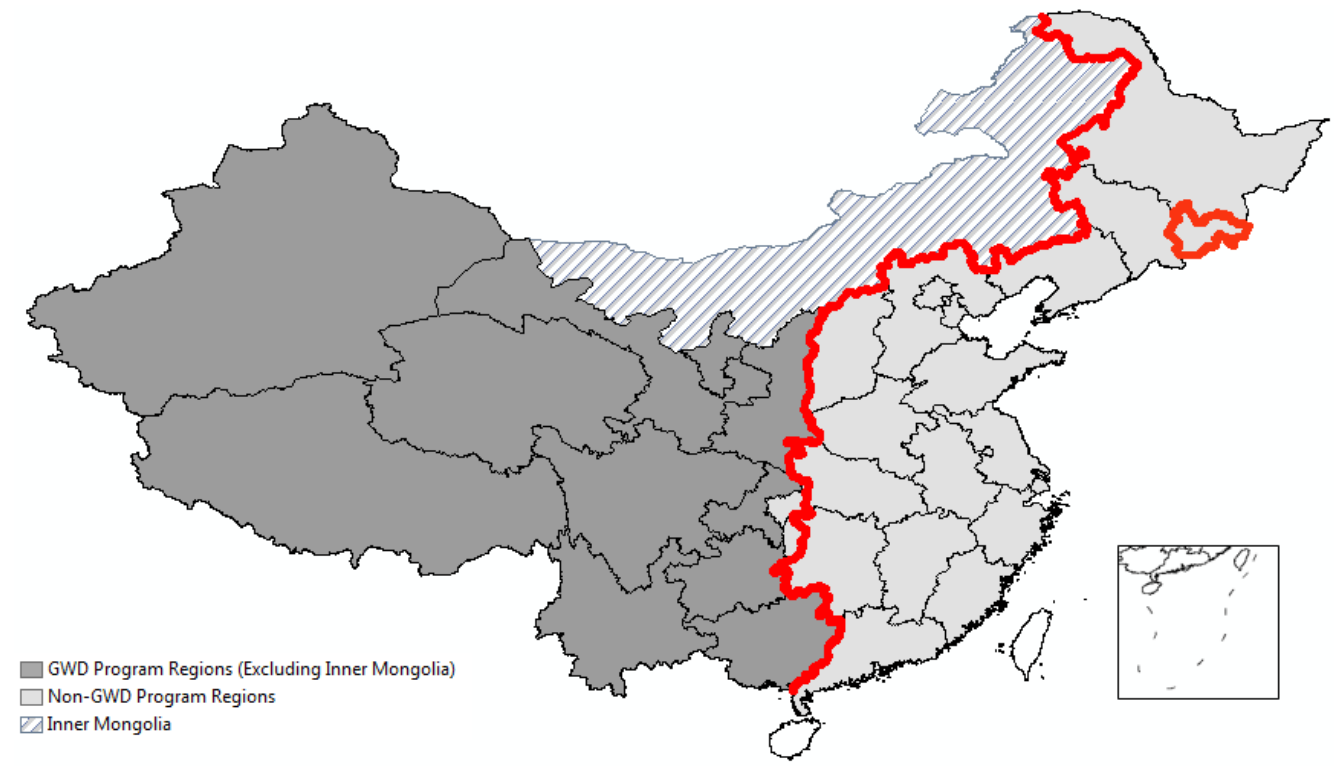

Fig. 1. The Map of the GWD Program. This figure displays the spatial distribution of the GWD Program. The GWD Program covers 12 provinces (Gansu, Guangxi, Guizhou, Inner Mongolia, Ningxia, Qinghai, Shaanxi, Sichuan, Tibet, Xinjiang, Yunnan, and Chongqing) as well as another three prefectures (Xiangxi in Hunan, Enshi in Hubei, and Yanbian in Jilin). The solid red line is the boundary of the program. Regions painted in thicker (lighter) gray are (not) covered. The program excludes 11 coastal provinces located in Eastern China and eight inland provinces located in Central China. Inner Mongolia (indicated by the slashed lines) is not included in our baseline analysis. 


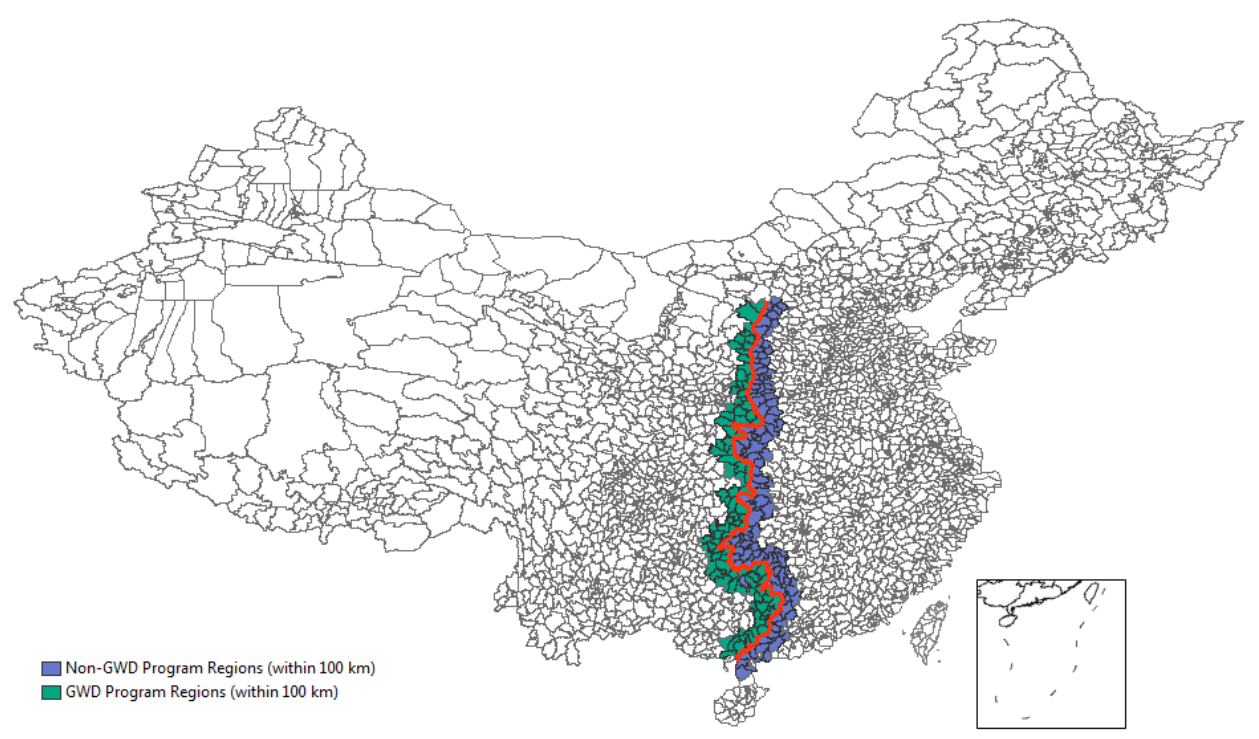

Fig. 2. The Map of GWD Program counties within $100 \mathrm{~km}$ of the boundary. This figure displays the spatial distribution of the counties within $100 \mathrm{~km}$ of the GWD Program boundary. Counties in blue form the control group, and counties in green comprise the treatment group. Regions outside the 100-km bandwidth are left blank. 


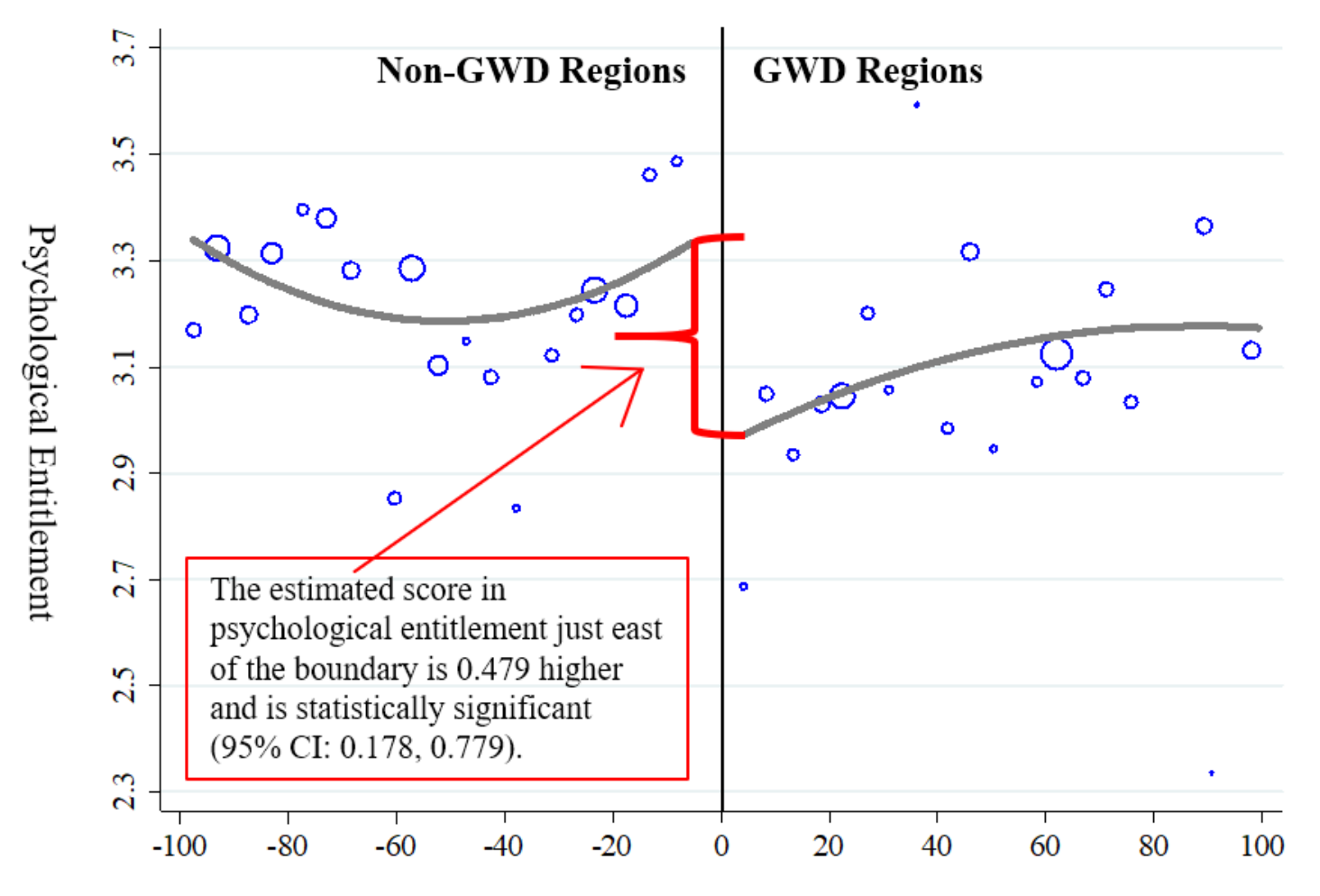

Distance to the Boundary

Fig. 3. Discontinuity of psychological entitlement scores across the GWD Program boundary. The $\mathrm{x}$-axis denotes a county's distance from the GWD Program boundary, where negative values are used for our control group. Each observation (circle) is generated by averaging scores within each bin $(5 \mathrm{~km})$. The size of the circle is proportional to the total population within each sample bin $(5 \mathrm{~km})$. The plotted line reports the fitted values from a regression of scores on a quadratic polynomial in distance. 


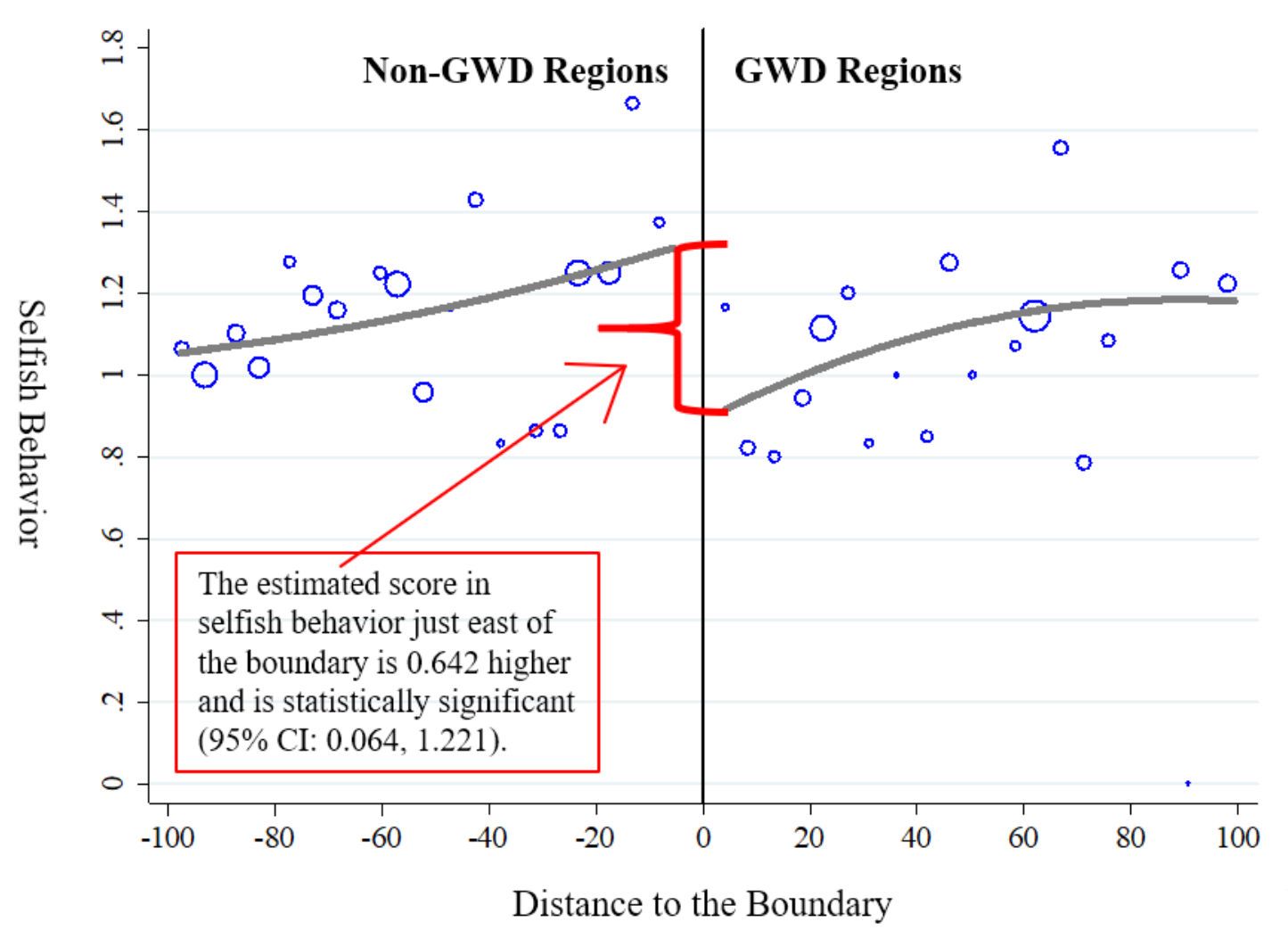

Fig. 4. Discontinuity of selfish behavior scores across the GWD Program boundary. The $\mathrm{X}$-axis denotes a county's distance from the GWD Program boundary, where negative values are used for our control group. Each observation (circle) is generated by averaging scores within each bin $(5 \mathrm{~km})$. The size of the circle is proportional to the total population within each sample bin $(5 \mathrm{~km})$. The plotted line reports the fitted values from a regression of scores on a quadratic polynomial in distance. 


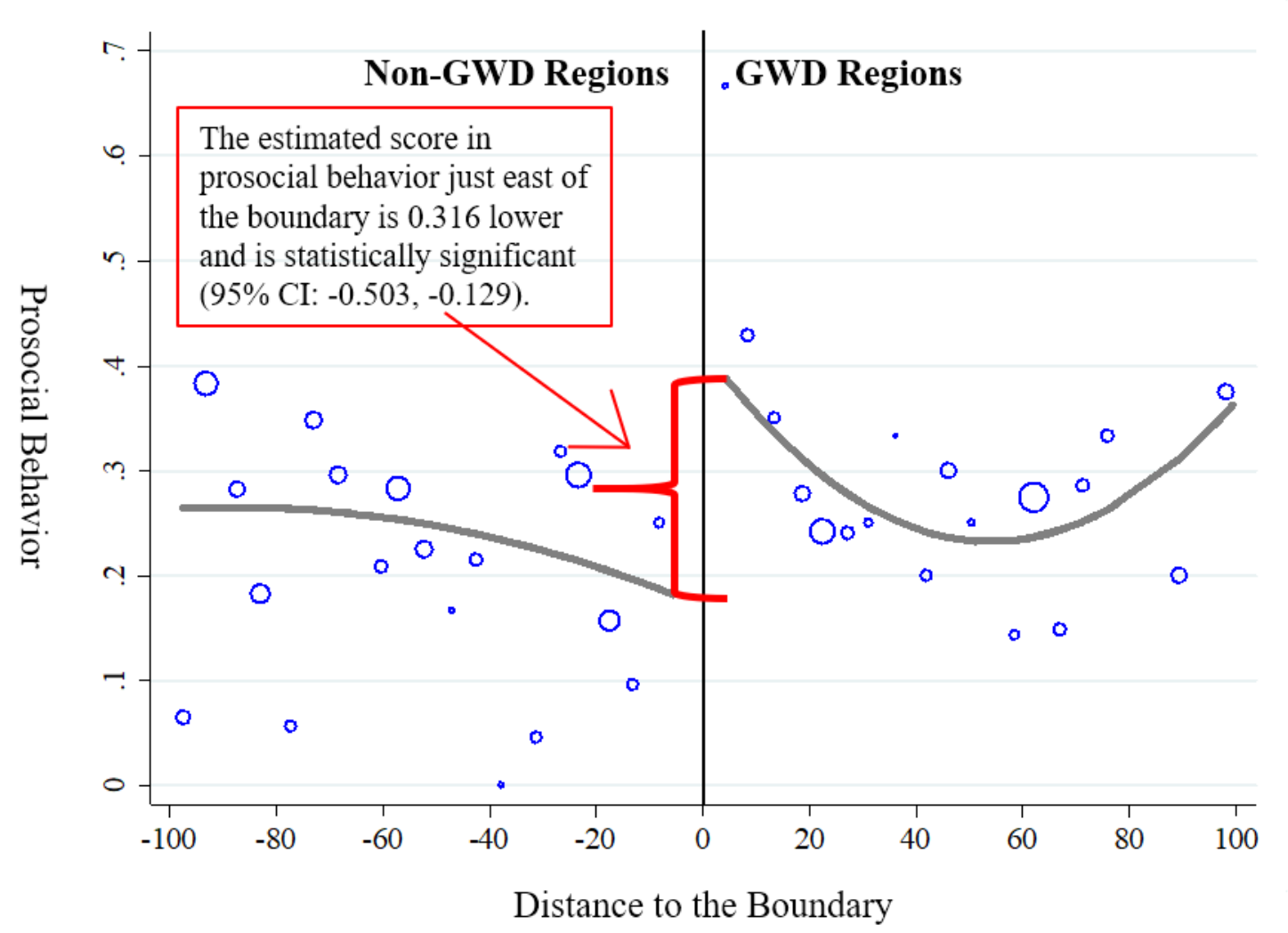

Fig. 5. Discontinuity of prosocial behavior scores across the GWD Program boundary. The x-axis denotes a county's distance from the GWD Program boundary, where negative values are used for our control group. Each observation (circle) is generated by averaging scores within each bin $(5 \mathrm{~km})$. The size of the circle is proportional to the total population within each sample bin $(5 \mathrm{~km})$. The plotted line reports the fitted values from a regression of scores on a quadratic polynomial in distance. 
Table 1. Balance test

\begin{tabular}{lccccc}
\hline & $(1)$ & $(2)$ & $(3)$ & $(4)$ & $(5)$ \\
\cline { 2 - 6 } Variable & Gender & Hukou status & Age & Education & $\begin{array}{r}\text { Annual } \\
\text { income }\end{array}$ \\
\hline GWD & -0.067 & -0.038 & 0.067 & 0.747 & -0.333 \\
dummy & $(0.807)$ & $(0.110)$ & $(0.110)$ & $(2.145)$ & $(0.272)$ \\
RD & quadratic & quadratic & quadratic & quadratic & quadratic \\
polynomial & 1,247 & 1,247 & 1,247 & 1,247 & 1,247 \\
Observations & 0.009 & 0.003 & 0.012 & 0.006 & 0.007 \\
R-squared & 0
\end{tabular}

Each column in the table presents the results from a separate regression, which is estimated with a quadratic control for distance from the GWD boundary and its interaction with the GWD dummy. The bandwidth is $100 \mathrm{~km}$ from the GWD boundary. Estimated coefficients for the controls are not reported. ${ }^{*}$ Significant at $10 \%, * *$ significant at $5 \%, * * *$ significant at $1 \%$. 
Table 2. Baseline regression discontinuity estimates

\begin{tabular}{lccc}
\hline & $(1)$ & $(2)$ & $(3)$ \\
Variable & Psychological entitlement & Selfish behavior & Prosocial behavior \\
\hline GWD dummy & $-0.479^{* * *}$ & $-0.642^{* *}$ & $0.316^{* * *}$ \\
& $(0.153)$ & $(0.295)$ & $(0.095)$ \\
Demographic controls & YES & YES & YES \\
RD polynomial & quadratic & quadratic & quadratic \\
Observations & 1,247 & 1,247 & 1,247 \\
R-squared & 0.052 & 0.022 & 0.032 \\
\hline
\end{tabular}

Each column in the table presents the results from a separate regression. All regressions control for a vector of the demographic controls listed in Table 1. The bandwidth is $100 \mathrm{~km}$ from the GWD boundary. Estimated coefficients for the controls are not reported. $*$ Significant at $10 \%, * *$ significant at $5 \%, * * *$ significant at $1 \%$. 
Table 3. Regression discontinuity estimates of the mediating role of psychological entitlement

(1) (2)

\begin{tabular}{lcc} 
Variable & Selfish behavior & Prosocial behavior \\
\hline GWD dummy & $-0.555^{*}$ & $0.293^{* * *}$ \\
& $(0.295)$ & $(0.095)$ \\
Psychological entitlement & $0.183^{* * *}$ & $-0.049^{* * *}$ \\
& $(0.054)$ & $(0.018)$ \\
Demographic controls & YES & YES \\
RD polynomial & quadratic & quadratic \\
Observations & 1,247 & 1,247 \\
R-squared & 0.031 & 0.038 \\
\hline
\end{tabular}

Each column in the table presents the results from a separate regression. All regressions control for a vector of the demographic controls listed in Table 1. The bandwidth is $100 \mathrm{~km}$ from the GWD boundary. Estimated coefficients for the controls are not reported. *Significant at $10 \%, * *$ significant at $5 \%, * * *$ significant at $1 \%$. 


\section{Supplementary Text}

Measure of psychological entitlement. To assess individuals' psychological entitlement, we used the nine-item psychological entitlement scale (Campbell et al., 2004). Participants were asked to indicate their agreement with each of the following items using a five-point Likerttype scale $(1=$ Strongly disagree, $5=$ Strongly agree $)$. The specific items were as follows:

1. I honestly feel I'm just more deserving than others.

2. Great things should come to me.

3. If I were on the Titanic, I would deserve to be on the first lifeboat!

4. I demand the best because I'm worth it.

5. I necessarily deserve special treatment.

6. I deserve more things in my life.

7. People like me deserve an extra break now and then.

8. Things should go my way.

9. I feel entitled to more of everything.

Task instructions for the measure of selfish behavior. To assess individuals' selfish behavior, we used the "dictator game." Participants received the following instructions: "The following game will be played simultaneously by you and another anonymous participant A who connects over the Internet. A is another participant who is doing this study and is randomly assigned by the system. The task of this game is to assign bonus points. You and A will be randomly assigned to either the role of decision maker or receiver. Now there are 10 points. The decision maker can decide how many points he or she wants to keep for him- or herself and how many he or she wants to give to the receiver. Once the decision has been made, the receiver can only accept it. Now, your randomly assigned role is decision maker. How many points will you assign to the receiver?"

Task instructions for measure of prosocial behavior. To assess individuals' prosocial 
behavior, we focused on a specific behavior-helping researchers by completing an additional research task without rewards. At the end of the study, participants received the following instructions: "Our research team is currently working on another study. This study takes about five minutes, and there is no reward or bonus points for participation. Would you like to help us by participating in this study? (Note: Whether you choose to participate is up to you, and the choice will not affect the amount of bonus points you get in this study). If your answer is yes, please leave your email address, and we will send a questionnaire link to you later." 
Table S1. Regression discontinuity estimates of alternative bandwidths

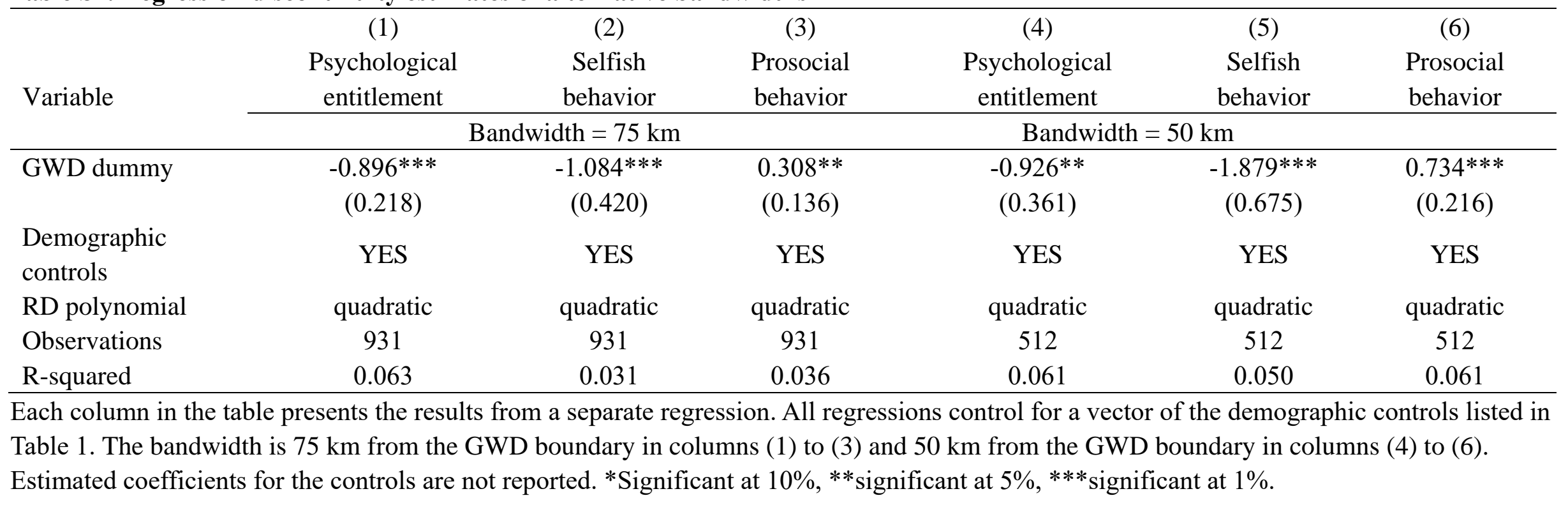


Table S2. Baseline regression discontinuity estimates: Linear polynomials

\begin{tabular}{lccc}
\hline & $(1)$ & $(2)$ & $(3)$ \\
Variable & Psychological entitlement & Selfish behavior & Prosocial behavior \\
\hline GWD dummy & $-0.219^{* *}$ & $-0.422^{* *}$ & $0.124^{* *}$ \\
& $(0.087)$ & $(0.167)$ & $(0.054)$ \\
Demographic controls & YES & YES & YES \\
RD polynomial & linear & linear & linear \\
Observations & 1,247 & 1,247 & 1,247 \\
R-squared & 0.049 & 0.021 & 0.026 \\
\hline
\end{tabular}

Each column in the table presents the results from a separate regression. All regressions control for a vector of demographic controls listed in Table 1. The bandwidth is $100 \mathrm{~km}$ from the GWD boundary. Estimated coefficients for the controls are not reported. *Significant at $10 \%, * *$ significant at $5 \%, * * *$ significant at $1 \%$. 
Table S3. Robustness of regression discontinuity estimates: Without demographic controls

(1) (2) (3)

Variable Psychological entitlement Selfish behavior Prosocial behavior

\begin{tabular}{lccc}
\hline GWD dummy & $-0.490^{* * *}$ & $-0.633^{* *}$ & $0.306^{* * *}$ \\
& $(0.156)$ & $(0.296)$ & $(0.096)$ \\
Demographic controls & NO & NO & NO \\
RD polynomial & quadratic & quadratic & quadratic \\
Observations & 1,247 & 1,247 & 1,247 \\
R-squared & 0.015 & 0.006 & 0.010 \\
\hline
\end{tabular}

Each column in the table presents the results from a separate regression. The bandwidth is $100 \mathrm{~km}$ from the GWD boundary. Estimated coefficients for the controls are not reported. *Significant at $10 \%, * *$ significant at $5 \%, * * *$ significant at $1 \%$. 
Table S4. Robustness of regression discontinuity estimates: Additionally controlling for segment effects
(1)
(2)

\begin{tabular}{lccc} 
Variable & Psychological entitlement & Selfish behavior & Prosocial behavior \\
\hline GWD dummy & $-0.461^{* * *}$ & $-0.635^{* *}$ & $0.324^{* * *}$ \\
& $(0.154)$ & $(0.297)$ & $(0.096)$ \\
Segment fixed effects & YES & YES & YES \\
Demographic controls & YES & YES & YES \\
RD polynomial & quadratic & quadratic & quadratic \\
Observations & 1,247 & 1,247 & 1,247 \\
R-squared & 0.060 & 0.023 & 0.041 \\
\hline
\end{tabular}

Each column in the table presents the results from a separate regression. All regressions control for a vector of the demographic controls listed in Table 1. The bandwidth is $100 \mathrm{~km}$ from the GWD boundary. Estimated coefficients for the controls are not reported.

*Significant at $10 \%, * *$ significant at $5 \%, * * *$ significant at $1 \%$. 
Table S5. Robustness of regression discontinuity estimates: Using the sample of people who were born in the same county they currently live in

(1)

\begin{tabular}{lccc} 
Variable & Psychological entitlement & Selfish behavior & Prosocial behavior \\
\hline GWD dummy & $-0.412^{* *}$ & $-0.873^{* * *}$ & $0.346^{* * *}$ \\
& $(0.169)$ & $(0.323)$ & $(0.104)$ \\
Demographic controls & YES & YES & YES \\
RD polynomial & quadratic & quadratic & quadratic \\
Observations & 986 & 986 & 986 \\
R-squared & 0.052 & 0.028 & 0.041 \\
\hline
\end{tabular}

Each column in the table presents the results from a separate regression. All regressions control for a vector of the demographic controls listed in Table 1. The bandwidth is $100 \mathrm{~km}$ from the GWD boundary. Estimated coefficients for the controls are not reported.

*Significant at $10 \%, * *$ significant at $5 \%, * * *$ significant at $1 \%$. 
Table S6. Heterogeneity

\begin{tabular}{|c|c|c|c|c|c|c|c|c|c|}
\hline Variable & $\begin{array}{c}\text { (1) } \\
\text { Psychological } \\
\text { entitlement } \\
\end{array}$ & $\begin{array}{c}(2) \\
\text { Selfish } \\
\text { behavior }\end{array}$ & $\begin{array}{c}(3) \\
\text { Prosocial } \\
\text { behavior } \\
\end{array}$ & $\begin{array}{c}(4) \\
\text { Psychological } \\
\text { entitlement }\end{array}$ & $\begin{array}{c}(5) \\
\text { Selfish } \\
\text { behavior } \\
\end{array}$ & $\begin{array}{c}\text { (6) } \\
\text { Prosocial } \\
\text { behavior }\end{array}$ & $\begin{array}{c}\text { (7) } \\
\text { Psychological } \\
\text { entitlement }\end{array}$ & $\begin{array}{c}(8) \\
\text { Selfish } \\
\text { behavior } \\
\end{array}$ & $\begin{array}{c}(9) \\
\text { Prosocial } \\
\text { behavior }\end{array}$ \\
\hline GWD dummy & $\begin{array}{c}-0.460 * * * \\
(0.160)\end{array}$ & $\begin{array}{c}-0.736 * * \\
(0.307)\end{array}$ & $\begin{array}{c}0.316^{* * *} \\
(0.099)\end{array}$ & $\begin{array}{c}-0.490 * * * \\
(0.158)\end{array}$ & $\begin{array}{c}-0.645^{* *} \\
(0.303)\end{array}$ & $\begin{array}{c}0.272 * * * \\
(0.098)\end{array}$ & $\begin{array}{c}-0.587 * * * \\
(0.207)\end{array}$ & $\begin{array}{c}-1.415 * * * \\
(0.396)\end{array}$ & $\begin{array}{c}0.395 * * * \\
(0.129)\end{array}$ \\
\hline $\begin{array}{l}\text { GWD dummy } \times \\
\text { Gender }\end{array}$ & $\begin{array}{l}-0.033 \\
(0.080)\end{array}$ & $\begin{array}{l}0.166 \\
(0.154)\end{array}$ & $\begin{array}{l}0.000 \\
(0.050)\end{array}$ & & & & & & \\
\hline $\begin{array}{l}\text { GWD dummy } \times \\
\text { Hukou status }\end{array}$ & & & & $\begin{array}{l}0.025 \\
(0.081)\end{array}$ & $\begin{array}{l}0.005 \\
(0.155)\end{array}$ & $\begin{array}{l}0.096^{*} \\
(0.050)\end{array}$ & & & \\
\hline $\begin{array}{l}\text { GWD dummy } \times \\
\text { Age }\end{array}$ & & & & & & & $\begin{array}{c}0.003 \\
(0.004)\end{array}$ & $\begin{array}{c}0.023 * * * \\
(0.008)\end{array}$ & $\begin{array}{l}-0.002 \\
(0.003)\end{array}$ \\
\hline $\begin{array}{l}\text { Demographic } \\
\text { controls } \\
\text { RD polynomial }\end{array}$ & $\begin{array}{c}\text { YES } \\
\text { quadratic }\end{array}$ & $\begin{array}{c}\text { YES } \\
\text { quadratic }\end{array}$ & $\begin{array}{c}\text { YES } \\
\text { quadratic }\end{array}$ & $\begin{array}{c}\text { YES } \\
\text { quadratic }\end{array}$ & $\begin{array}{c}\text { YES } \\
\text { quadratic }\end{array}$ & $\begin{array}{c}\text { YES } \\
\text { quadratic }\end{array}$ & $\begin{array}{c}\text { YES } \\
\text { quadratic }\end{array}$ & $\begin{array}{c}\text { YES } \\
\text { quadratic }\end{array}$ & $\begin{array}{c}\text { YES } \\
\text { quadratic }\end{array}$ \\
\hline Observations & 1,247 & 1,247 & 1,247 & 1,247 & 1,247 & 1,247 & 1,247 & 1,247 & 1,247 \\
\hline R-squared & 0.052 & 0.023 & 0.032 & 0.052 & 0.022 & 0.035 & 0.053 & 0.029 & 0.032 \\
\hline
\end{tabular}


Table S6. (continued)

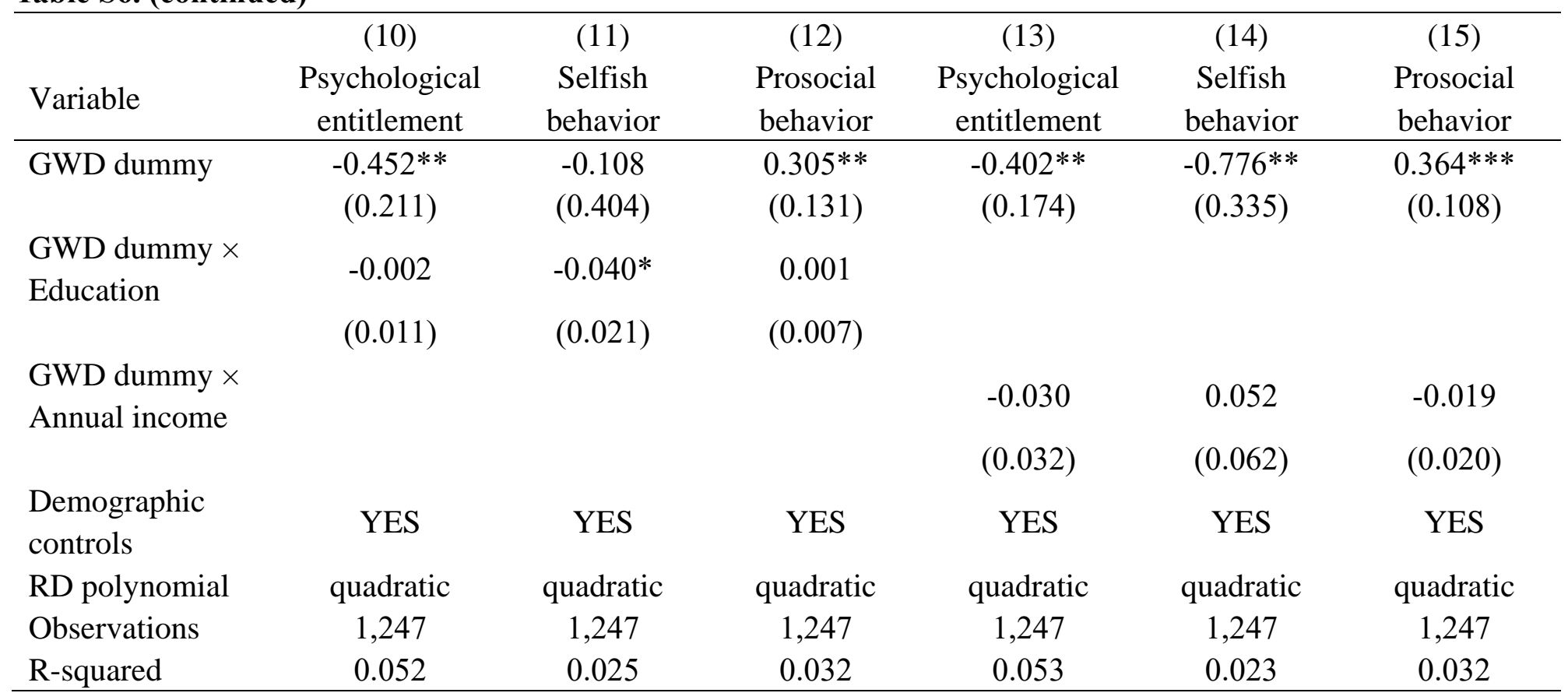

Each column in the table presents the results from a separate regression. All regressions control for a vector of the demographic controls listed in Table 1. The bandwidth is $100 \mathrm{~km}$ from the GWD boundary. Estimated coefficients for the controls are not reported. *Significant at $10 \%$, **significant at $5 \%, * *$ significant at $1 \%$. 